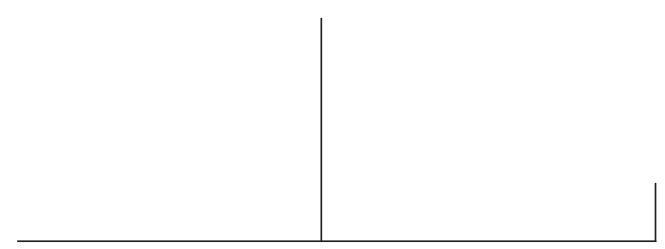

Rev. Latinoam. Psicop. Fund., II, 3, 89-95

\title{
A direção do tratamento e o uso do psicofármaco
}

Gilda Paoliello

A partir da demarcação das diferenças entre o sintoma psiquiátrico e o psicanalítico e da especificidade do psicofármaco dentro da medicina, a autora discute a importância de a psicanálise acompanhar os avanços da psicofarmacologia assim como a importância de não se desvincular os conceitos operativos da psicanálise, tais como a transferência e o conceito de sujeito, do ato de medicar.

Palavras-chave: Psiquiatria, psicanálise, sintoma psiquiátrico, sintoma psicanalítico, psicofármaco 


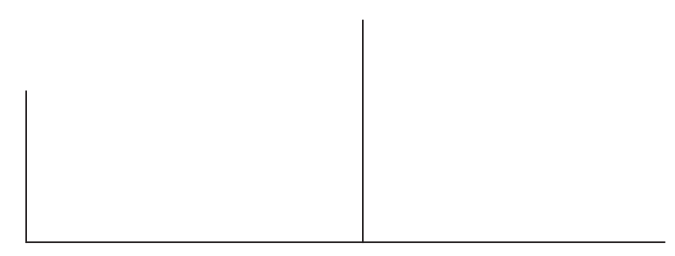

Durante toda a sua obra, Freud esteve atento às possibilidades que o desenvolvimento da ciência traria ao campo psi, embora deixasse claro que a tarefa da psicanálise era descobrir a função do inconsciente e suas conseqüências sobre a vida psíquica. Também Lacan demonstrava esse interesse ao instituir, no ato da fundação da Escola Freudiana de Paris, a seção de Psicanálise Aplicada, atribuindo aos médicos a função de contribuir para a experiência psicanalítica e vice-versa.

Hoje, o desenvolvimento das neurociências, particularmente da psicofarmacologia, é um fato, e deixar de considerá-lo seria, para o psicanalista, uma posição retrógrada ou, pior ainda, de recusa perversa. A psicofarmacologia oferece-nos, sem dúvida, importantíssimos recursos, e seria uma grave omissão deles não lançarmos mão. Porém, medicar, em psiquiatria, não é um ato simples e nunca se reduzirá a um diagnóstico e uma pílula. Muitas variáveis atuam sobre essa prática: além da seleção das drogas, que devem ser sempre feitas a partir da observação direta e do conhecimento das especificidades dos neurotransmissores, devemos levar em conta que a prescrição é um ato que nunca deve ser isento da participação do sujeito e que, se os neurotransmissores são conhecidos, a estrutura só é alcançada através das fantasias e substituições sintomáticas. O Édipo não pode ser deduzido pelas neurociências, e a formação do delírio não deriva do conhecimento dos neurotransmissores.

Apesar dos avanços trazidos pelo recurso farmacológico, observamos um triste fenômeno dentro da psiquiatria atual: um desinteresse crescente pela observação clínica em sua riqueza de 


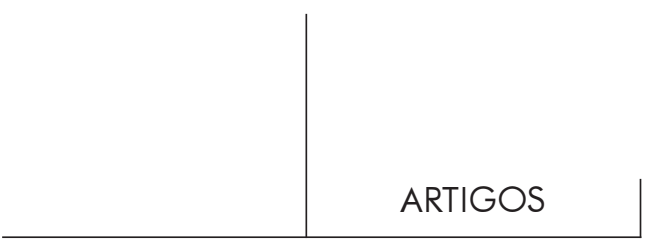

detalhes, pervertendo o ponto de partida do diagnóstico. A psiquiatria atual vem invertendo os valores, diagnosticando em função do tratamento, fazendo-nos pensar que, em vez de "para novos males, novos remédios", a indicação é "para novos remédios, novos males". Esse sintoma revela a crise que a psiquiatria vem conhecendo, paradoxalmente, desde o surgimento dos antidepressivos, e que o DSM4 só faz acentuar ainda mais, já que seu princípio é estabelecer uma classificação das enfermidades a partir do tratamento, excluindo o sujeito. A psiquiatria precisa, urgentemente, resgatar o olhar clínico, substituído que vem sendo pelo panopticon das neurociências.

Por outro lado, percebo também, com honrosas e raras exceções, uma posição de incoerência, de passividade, de omissão e até de irresponsabilidade da psicanálise em desconsiderar - ou considerar mal - o papel do psicofármaco. Vejo, freqüentemente, psicanalistas mostrarem uma postura crítica em relação ao uso da medicação, denunciar seus abusos (que são mais que verdadeiros e nocivos, levando a verdadeiras toxicomanias), mas sem se preocuparem em acompanhar o real avanço da psicofarmacologia e suas reais contribuições para a clínica.

Sabemos que grande parte de psicanalistas que têm formação médica, medicam e medicam mal. Sabemos, também, que grande parte de psicanalistas não médicos resistem ou não sabem quando encaminhar seu analisantes para avaliação da possibilidade de medicação. Vemos, com freqüência, psicanalistas atravessando o Atlântico em busca de supervisão, o que - é claro -, é bastante interessante, mas, rarissimamente, os vemos abrindo um livro ou se submetendo a uma supervisão em farmacologia a fim de se atualizarem.

Por tudo isso, emocionou-me a presença, em Belo Horizonte, do psicanalista e psiquiatra italiano Carlo Viganó, por sua preocupação em elaborar e formalizar a interação da psicofarmacologia e da psicanálise e suas conseqüências. Conseguiu executar essa façanha com brilho. A AMP, responsável, juntamente com o Instituto de Saúde Mental, por sua vinda ao Brasil, sente-se também na responsabilidade de divulgar as reflexões de Viganó e de continuar estimulando esse debate.

É mais que hora de ocuparmo-nos dele pois, se não o fizermos, entregaremos a Clínica Psiquiátrica àqueles que consideram o homem "muito enzima", como definiu o Presidente do Congresso Mundial de Psiquiatria, ocorrido no Rio de Janeiro, em 1993.

Para discorrermos sobre a direção do tratamento e o uso do psicofármaco, é imprescindível marcarmos alguns pontos fundamentais com relação ao sintoma, demarcando as diferenças entre o sintoma psiquiátrico e o psicanalítico e com relação ao psicofármaco. 


\section{Com relação ao sintoma}

Freud, freqüentemente, comparava a psicanálise à medicina, no sentido de apontar as diferenças, principalmente em relação aos conceitos de cura e de sintoma nos dois registros.

Em medicina, o sintoma, como nos diz Foucault, é um significante atrelado à doença, seu significado e sua causa são alheios ao sujeito.

$$
\frac{\text { Sintoma }}{\text { Doença }}=\frac{S}{\mathrm{~s}}
$$

A definição de sintoma, em psiquiatria, é tomada deste modelo médico. Restanos saber se o sintoma psiquiátrico "cabe" dentro deste modelo. Voltaremos a isso. Passemos ao sintoma, na psicanálise.

Em psicanálise, o sintoma é expressão de um conflito psíquico que indica a divisão do sujeito e sua estrutura é significante, implicando o sujeito do inconsciente. É da ordem da metáfora, é um significante que vem no lugar de outro, recalcado. O sintoma tem o valor de mensagem cifrada, permitindo ao analista completá-lo, ao ocupar o lugar de sujeito suposto saber. $\mathrm{O}$ analista deve procurar saber a que este sintoma está respondendo, que gozo ele traz. $\mathrm{O}$ analista deve se fazer a seguinte questão, como direção para o tratamento: "O que fez falhar o recalque e surgir o retorno do recalcado para que fosse constituído o sintoma?"1

Enquanto o sintoma faz parte da vida da pessoa, pode ser considerado como um sinal - aquilo que representa alguma coisa para alguém. Quando esse sintoma é transformado em questão, ele aparece como expressão de divisão do sujeito. É nesse momento que o sintoma encontra o endereço certo - o analista - tornando-se sintoma propriamente analítico. Nesse momento, o sujeito se dirige ao analista com uma pergunta: "O que é isso?" - pedindo-lhe a decifração do sintoma, supondo que o analista sabe sobre ele.

E a demanda feita ao psiquiatra, é diferente? Às vezes não, às vezes sim. É diferente quando a demanda é feita, não pelo sujeito, mas pela família, pela instituição, pela sociedade. Sabemos que nem sempre o paciente procura o psiquiatra pelas próprias pernas, mas, muitas vezes, vem trazido por uma dessas partes, e que, nessas situações, ele é quase sempre incapaz de comunicar sua queixa - a queixa é ele próprio.

1. Antônio Quinet. As $4+1$ condições da análise. Coleção Campo Freudiano no Brasil. Rio de Janeiro, Jorge Zahar, 1991. 


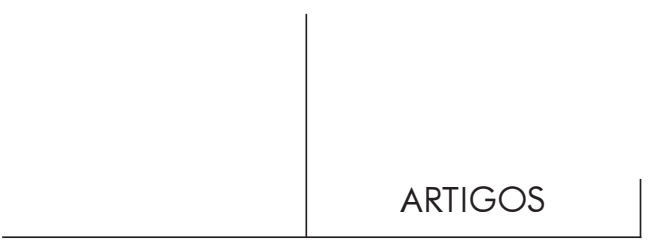

Mas, outras vezes, o paciente chega ao psiquiatra com uma transferência já estabelecida. A questão é o que o psiquiatra faz com ela. Como nos diz Lacan em "A proposição de 9 de outubro": "Ela está aí por graça do analisante. Não temos de dar conta do que a condiciona. Aqui ela está desde o início”. A função do analista é saber utilizá-la.

A posição da psiquiatria como ciência é, cada vez mais, excluir o sujeito. O discurso da ciência rejeita o sujeito e não se questiona sobre o desejo, ignorando os efeitos provocados no pesquisador pelo objeto de sua pesquisa. Nessa posição, o psiquiatra ignora o fenômeno transferencial e se exclui do sintoma. Sabemos que essa posição não satisfaz. O modelo médico não dá conta do sintoma psiquiátrico. Até os psiquiatras biológicos, cegos da transferência, que adota critérios científicos para a correlação sintoma-causa, reconhece que ainda não é possível estabelecer definitivamente essa correlação. Eles trabalham com suposições empíricas. O psiquiatra não pode ficar preso à vertente sintoma/doença. Ele deve fazer com que o sujeito queira saber sobre a causalidade psíquica.

Para Freud, o efeito terapêutico se obtém pelo deciframento dessa mensagem que é o sintoma, na transferência. Assim, o analista se insere no sintoma através da transferência. Mas sabemos que este fenômeno não é exclusivo da análise como nos indica Lacan, no Seminário XI: "Cada vez que, para o sujeito, essa função do sujeito suposto saber é enfocada por quem quer que seja, analista ou não, isso significa que a transferência já está estabelecida", e o sintoma estará relacionado a essa transferência.

\section{Com relação ao Psicofármaco}

Este também tem estatuto de exceção dentro da medicina: não se baseia em mecanismo de ação e patogênese da doença. "As teorias que tentam explicar o mecanismo de ação destas drogas têm-se mostrado um tanto inconsistentes e a cada dia vêm sendo reformuladas em um ou outro ponto. A conclusão é que o empirismo rege a prática do tratamento medicamentoso". ${ }^{2}$

Basta olharmos como são grandes as variações entre a dose e o efeito de uma mesma medicação para diferentes indivíduos que têm um mesmo diagnóstico, como um fármaco que foi positivo para um e não o é para outro, e, mesmo para um mesmo indivíduo, não faz o mesmo efeito em dois tempos distintos. Fica claro que, em psiquiatria, não se tem a mesma objetividade para se indicar uma medicação, como nas outras especialidades.

2. Márcia Montezuma. "Ato nem tão milagroso nem tão danoso". O Risco, ano X, $\mathrm{n}^{\underline{0}}$ 2, dezembro de 1997. 


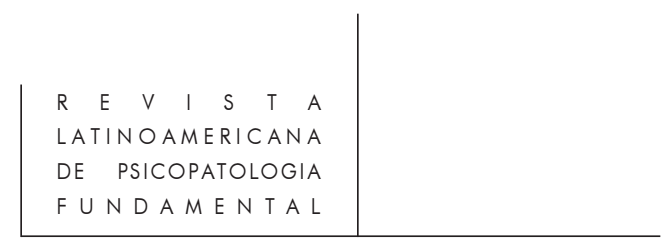

Muitas vezes o remédio entra como significante no discurso do sujeito e, nesses casos, deve ser trabalhado também nesse registro. Para além da indicação médica, que é soberana, devemos avaliar o que do recurso da medicação pode ser utilizado como tática e como estratégia na conclusão do tratamento. O remédio deve vir a cumprir também a função de ato, de interpretação ou de suplência e, uma vez inserido no discurso do sujeito, tornar-se também analisável. ${ }^{3}$

A instância técnica da medicação deve ter também uma força simbólica, atuando na transferência.

Por fim, devemos lembrar que o remédio, para o apaziguamento do desejo, é a psicanálise; e que a indústria farmacêutica não tem como apaziguar o mal-estar do desejo.

"O homem é muito enzima", ouço de um colega. "O sujeito é efeito da linguagem", dispara outro. A palavra, recurso da estrutura simbólica que nos mantém como seres desejantes, causa e sofre efeitos de um substrato biológico, da mesma forma que a biologia humana necessita da hipótese do sujeito a todo momento em que se queira explicar os fenômenos da clínica.

Lembro-me aqui de dois personagens de Ítalo Calvino, também citados por Ana Maria Portugal no texto "Sujeito e linguagem". O primeiro personagem, uma surpreendente armadura, impecavelmente polida e sem nada por dentro, apenas uma voz metálica que se dedica inteira à causa de seu país. Não é tocada pelos sentidos, pelas paixões, não sente fome, cansaço, alegria ou angústia. É puro simbólico, sustentando a causa e a ordem sem tropeços, sem claudicâncias, sem divisões. O outro personagem, o Escudeiro, um ser amorfo, que vai se amoldando a tudo o que passa por perto - animais, plantas, coisas, e daí vai ganhando diferentes nomeações - pura enzima, nada de sujeito.

Somos feitos da matéria dos sonhos, sustentados por um corpo que se tornará pó - nem pura enzima, nem puro simbólico. Claudicantes. O paciente, o sintoma, o psiquiatra e o psicanalista devem caminhar juntos, de braços dados, mesmo claudicando, sabendo que nem tudo é compatível. Mesmo caminhando de mãos dadas, a psiquiatria e a psicanálise não marcham para um saber absoluto, como responde J.A. Miller a H. Etchegoyen, em histórica entrevista. Haverá sempre sombras.

Tomando emprestada uma metáfora usada por Jorge Forbes, podemos falar que para onde a psiquiatria avançar como saber, é das sombras desses avanços que a psicanálise vai se ocupar.

A articulação da psiquiatria com a psicanálise deve fazer o tratamento caminhar na direção da coincidência possível de uma causa entre os dois campos: introduzir no trabalho clínico a causa do sujeito, que é sua tendência específica para a

3. Idem, ibidem. 


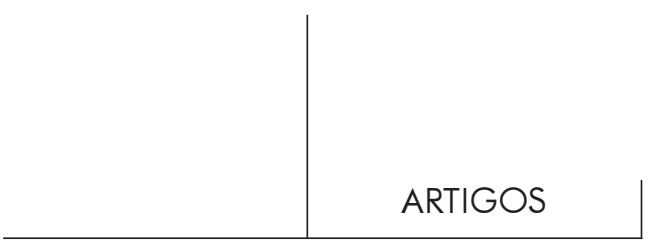

diferença. Com isso em vista, é possível a convivência da política do imprevisível da psicanálise com a política da supressão do psicofármaco, levando a uma mesma ética entre os dois campos psi: sustentar aquilo que se deduz da clínica.

Junto ao produto da ciência e seus efeitos químicos, a psicanálise deve demonstrar como as modificações do sintoma pertencem à economia do gozo. Desta forma, a "operação fármaco", como a ela se refere Carlo Viganó, se torna falante em seus efeitos, tanto naqueles químicos quanto naqueles de natureza significante (como sugestão, transferência etc.).

Devemos nos lembrar que, antes de sofrer qualquer distúrbio de neurotransmissão, o homem é um ser (biológico, falante) que sofre de si mesmo e é desta paixão que ele deve se curar.

\section{Resumos}

Empezando por los aspectos diferenciales del síntoma psiquiátrico y del psicoanalítico y de la specificidad del fármaco en la Medicina, la autora discurre sobre el accento que hay que ponerse.

Entiende que el psicoanálisis debe acompañar los avances de la Psicofarmacologia y pone relieve que no se desate los conceytos del Psicoanálisis, que por ejemplo son sujeto y transferencia, del acto de medicar.

Palabras llave: Psiquiatria, psicoanálisis, síntoma psiquiátrico, síntoma psicoanalítico, psicofarmaco.

En partant de la démarcation des différences existantes entre les symptômes psychiatrique et psychanalytique aussi bien que de la spécificité du psychopharmacologique en médicine, l'auteur analyse l'importance, pour la psychanalyse, d'accompagner les avances de la psychopharmacologie et, en même temps, l'importance de ne pas détacher de l'acte médical des concepts opérationnels de la psychanalyse tels que ceux du "transfert" et du "sujet".

Mots clés: Psychiatrie, psychanalyse, symptôme psychiatrique, symptômes psychanalytique, psychopharmaco.

Taking into account the differences between the psychiatric and the psychoanalytical symptoms as well as the specificity of the psychopharmacological dimension in medicine, the author discusses the importance of psychoanalysis' keeping up with advances in psychopharmacology and at the same time the importance of not dissociating the medical act from such psychoanalytical operational concepts as "transfer" and "subject".

Key words: Psychiatry, psychoanalysis, psychiatric symptom, psychoanalytical symptoms, psychopharmacon. 